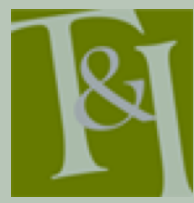

The International Journal for Translation \& Interpreting Research trans-int.org

\title{
Does interpreting 'steal' conflict? A translational perspective on power and restorative justice
}

\author{
Sarah Maitland \\ Goldsmiths, University of London \\ s.maitland@gold.ac.uk
}

DOI: 10.12807/ti.111201.2019.a02

\begin{abstract}
Restorative justice' enables the victims of crime to meet with those responsible and to talk about what happened. It is an opportunity for victims to find ways to move on and for offenders to understand the effects of their actions. In the restorative justice literature, it is often assumed that those involved in the restorative process share the same language and ability to understand and communicate. But what happens when communication between an offender and a victim must be mediated through an interpreter? This article considers from a theoretical perspective how the vehicles of restoration - interaction, participation and encounter - and their role in creating empathy between the parties to a crime may be affected when realized in a bi- or multilingual setting. By taking a translational view, that is, by conceptualizing the restorative encounter as a hermeneutic process in which all acts of communication result in understandings that are both provisional and contingent, this article brings the founding theories of restorative justice into critical conversation with theories of language and translation to examine the philosophical implications of interpreting for the restorative justice paradigm in general and the practical dimensions of interpreter-mediated restorative justice interventions in particular.
\end{abstract}

Keywords: restorative justice, hermeneutics, interpreting, interpreter-mediated communication

\section{Introduction and background}

In the UK, the National Occupational Standards for Restorative Practice is a suite of performance benchmarks identifying key competencies for successful interventions between a person harmed by a crime and the person responsible for causing the harm. Within the suite, a unit entitled "Use interpreters in restorative processes" covers the performance criteria, knowledge and understanding applicable to "anyone working within restorative practice who works with interpreters to enable participants to access restorative processes" (Skills for Justice, 2013e, p. 1). In a subsection entitled "Knowledge relating to the use of interpreters", the unit calls for restorative practitioners to understand the role of "power" in a restorative setting, "and how it can be used and abused when working with participants who require interpreters" (p. 6 ). The issue of power appears throughout the standards, in relation to minimizing "conflicts around differing understandings" (2013a, p. 6), agreeing on means of communication that "minimise potential for power imbalances" (p. 3), or creating a "safe environment" by "acknowledging diversity and difference between participants" (2013d, p. 2). No explanation is given as to what power looks like, who exercises it, or what constitutes its "abuse" when interpreters are concerned. But in each of the occupational standards where the notion of power is invoked, the term is modified either by "imbalance(s)" between parties (2013a, p. 3, p. 7; 2013b, p. 6; 2013c, p. 4; 
2013d, p. 2, p.5) or by "group dynamics" (2013a, p. 7; 2013b, p. 6; 2013d, p. 5 ), and on one occasion appears alongside a reference to "gender equality, racial and cultural difference" (2013c, p. 4). By taking this holistic view of the ways in which power is articulated across the standards, what becomes clear is that it is the intersubjective nature of restorative justice that raises issues of power, when victims and offenders as bearers of different individual and group identities - and the diversity of human experience this implies - come together to talk about a harmful incident which, by its very nature, positions them on opposing 'sides' and where the starting point for communicative interaction is the very breakdown of relationships that occasions the interaction in the first place. It is to this prismatic space that this article is addressed, where imbalances of power are linked inextricably to the performance of identity in the encounter with the ontological and linguistic 'other'.

The philosophy of empowerment (Braithwaite, 2006a, p. 396) that underpins restorative interventions - that power lies with primary stakeholders (i.e., those responsible for and harmed by a crime, their family members and/or supporters, and wider public) rather than with professionals engaged in supporting stakeholders or administrating justice - is shaped against a context of courtroom justice thought to increase, rather than diminish, feelings of unfairness and marginalization among victims and offenders. ${ }^{1}$ From a socalled 'restorative' perspective, crime is viewed as behaviour that causes harm; restorative responses are intended to promote the needs of the parties in response to harmful behaviour through processes that focus on participation, the expression of feelings and exchange of information in a supportive and collaborative environment. In the words of the UK Restorative Justice Council (RJC), restorative justice is about "victims and offenders communicating within a controlled environment to talk about the harm that has been caused and finding a way to repair that harm", giving victims "the chance to meet or communicate with their offenders to explain the real impact of the crime" and empowering them "by giving them a voice" (n.d.). But what happens to these ideals when victims and offenders do not speak the same language, or their level of proficiency is not equal? If an interpreter becomes involved, where is the locus of power when, of necessity, we move from a communicative constellation in which, in principle, there is no intended centre of gravity to one in which all speech both gravitates towards and emanates from the interpreter?

By situating this article against a theoretical backdrop of restorative justice in which the conventions of communication are founded on the presumption of monolingual discourse between speakers with the same level of language proficiency, and with a focus on restorative youth justice in Northern Ireland, I aim to consider how the vehicles of restoration interaction, participation and encounter - may be affected when realized in a bi- or multilingual setting. By taking a translational perspective, that is, by viewing the restorative encounter as a hermeneutic process in which all acts of communication result in understandings that are both provisional and contingent, I bring the founding theories of restorative justice into critical conversation with theories of language and translation to examine the philosophical implications of interpreting for the restorative justice paradigm in general and the practical dimensions of interpreter-mediated restorative justice interventions in particular.

\footnotetext{
1 Professionals engaged in supporting stakeholders or administrating justice encompasses state actors, such as representatives of the justice system, as well as nonstate actors, such as legal services, victim support, advocacy services, or immigration or trauma-informed professionals.
} 


\section{Conflicts as property}

For proponents of restorative justice, the retributive system wrests control from those harmed by crime and distributes the power to make decisions among state agencies. Restorative justice, by contrast, aims to transfer power by accommodating the diverse needs and wishes of those harmed most directly. A defining figure in this conceptualization is Christie, who argued in 1977 that conflicts between people are "stolen" by the organs of justice, such that something that begins as the immediate concern of the concrete parties to a conflict is transformed into a conflict between only one party and the state:

So, in a modern criminal trial, two important things have happened. First, the parties are being represented. Secondly, the one party that is represented by the state, namely the victim, is so thoroughly represented that she or he for most of the proceedings is pushed completely out of the arena, reduced to the triggereroff of the whole thing. She or he is a sort of double loser; first, vis-à-vis the offender, but secondly and often in a more crippling manner by being denied rights to full participation in what might have been one of the more important ritual encounters in life. The victim has lost the case to the state (Christie, 1977, p. 3).

Conflicts are taken away from those involved, and either disappear or end up as the property of learned others who alone have the power to decide what is relevant in a case and what the punishment should be. A 'property' of the people becomes the property of lawyers and other authorities charged with executing the rule of law. The effect is profound:

The victim is a particularly heavy loser in this situation. Not only has he suffered, lost materially or become hurt, physically or otherwise. And not only does the state take the compensation. But above all he has lost participation in his own case. It is the Crown that comes into the spotlight, not the victim. [...] Something that belonged to him has been taken away from that victim (Christie, 1977, pp. 7-8).

As trauma-informed services and researchers have emphasized, for victims, the loss of a sense of power and control over their own legal process can be debilitating. To the extent that 'we' are society, moreover, one of the biggest losses is the opportunity to question - what we mean by 'victim' and 'offender'; what motives to attribute; what blame to apportion; what redress to seek and to what extent this should vary according to the circumstances of different victims and different offenders, etc. Political debate is stifled, victims become humiliated and excluded, and offenders are prevented from offering reasons for their actions (p. 9).

Christie's thesis, that the state distorts restorative justice values to fit its priorities rather than those of victims, offenders, and wider community, finds expression in a recent comparative analysis of the findings of two empirical studies of restorative justice practices in the UK, led by Hoyle \& Fonseca Rosenblatt (2016), who wrote of "a professional culture shaping and often distorting the restorative process" (p. 44), that fails to provide a meaningful role for community members, and which contributes to poor victim involvement (p. 34). This view resonates with that of Gerkin (2012), who argued that because crimes in the USA are seen primarily as a violation against the state, responses to conflict are "monopolized" by criminal justice professionals, resulting in a significant erosion of the place of victims and communities (p. 277). In the context of the Youth Justice Group Conferencing Program in Victoria, Australia, Suzuki and Wood (2017) have likewise written of the "co-option" (p. 22) of restorative justice practices for systemic goals at odds with the needs of victims and offenders (such as participation, 
redress, accountability, and amends), and the attendant problem of institutional "gatekeepers" who hold power over the decision of whether or not to use restorative justice (p. 24).

The alternative that Christie outlined was a victim-oriented approach that would recognize not only that people have reasons for their actions but also that if those reasons could be given in a space where the focus is not on apportioning guilt but on somehow making up for what has been done, the sense of humiliation and exclusion that tends to accompany criminal proceedings might change. For Christie, when victims are "re-introduced" to the cases from which they have been excluded, meaningful attention can be paid to their losses $(1977$, p. 9). This would mean raising victims to the status of equal partners in the development of shared pathways towards justice and healing, and, from an economic perspective, the potential for a reduction in costs could make it possible for more cases to be pursued. The offender would go from hearing about their punishment to contributing directly to a discussion of how to compensate for what they have done. In this way, conflicts would not be removed by professional intermediaries or institutional organs from the people most directly affected, but would instead "become useful for those originally involved" (p. 1).

\subsection{Restorative youth justice in Northern Ireland}

While many forms of restorative justice are in operation globally, the Northern Ireland model of youth conferencing presents a useful example of victim and offender interaction through which to explore the challenges of communication in an interpreter-mediated setting. Influenced by the family group conference approach in New Zealand and the balanced model in the United States, restorative justice is fully integrated within the Northern Ireland criminal justice system, and by legislative mandate restorative group 'conferences' must be offered to all young people who admit to a criminal offence, except where a mandatory life sentence would be imposed in the case of adult offenders. All youth conferences are managed by the Youth Justice Agency (YJA), which is an executive agency within the Department of Justice, and while the restorative route must at least be explored in all relevant cases, the decision to participate lies with those responsible for the harm and their victims, rather than with criminal justice professionals (Chapman, 2012).

Conferences in Northern Ireland can tackle the full spectrum of offences, from minor crimes to serious violent and sexual offences, and this means that the people who choose to take part are diverse - they may be vulnerable or have disabilities or face other challenges which affect their ability to communicate or empathize - and the relationship between them may be close or distant, and their feelings towards one another may range from indifference to antagonism, fear or dread (Chapman, 2012, p. 3). In recognition, the Northern Ireland model is predicated on offering flexibility and accessibility to a diverse range of people affected in differing ways and to differing degrees by a diverse range of harmful acts. It is also a model that seeks a balance between the needs and interests of those affected by and responsible for harm and those of the wider community. As Chapman (2012) explains, "a restorative justice approach embedded within the criminal justice system cannot disregard the reality that youth crime is a public issue and not simply a private matter between the victim and the offender" (pp. 3-4). In this conceptualization, restorative justice is concerned with more than a breach of law and focuses instead on the full range of actors impacted by a crime, which it views as an opportunity to involve communities in conflict resolution, to support victims and offenders and repair harm - goals which would be impossible to achieve without community participation (Gerkin, 2012, p. 278). This approach means that many people can and should be included in the conference and that each of these "affected communities" (Zehr \& Mika, 
1998) will have a different relationship to the harm, and different needs that must be communicated and satisfied as a result.

The conference itself is managed by a youth conference coordinator trained by the YJA. In other processes this figure is sometimes referred to as a 'facilitator', and in this article the terms 'coordinator' and 'facilitator' are used interchangeably. The young person will be present, alongside a parent or carer. A youth diversion police officer will be in attendance, as well as any probation officers or social workers for the young person. The young person's lawyer may attend but cannot advocate on their behalf. Every effort is made to enable the victim to participate, but a conference can take place even when they are not present. The coordinator encourages the participants to discuss what happened and what effect it had upon them, and to come to an agreement about what actions the young person should undertake to repair the harm. Once an action plan has been agreed it becomes an enforceable court order supervised and supported by the YJA. ${ }^{2}$

\subsection{Empowerment through encounter}

At the heart of all restorative encounters is a commitment to inclusion, participation and empowerment. Uniting these ideals is the principle of constructive communication - the opportunity for victims and offenders to speak to one another and to be heard. This dialogical element is essential for the parties to a crime to feel in control of what they want to say and ask, and that their needs and interests have been met, endowing victims and offenders disempowered by the adversarial system with the means and opportunity to experience what it is like to have their stories heard, to listen to the story of others, and to take charge over what should happen next (Zinsstag \& Chapman, 2012, p. 7).

The primacy of dialogue is evident as much in the discourse of the statutory agencies charged with delivering restorative justice as it is in the academic literature. According to the YJA victim information leaflet, for example:

The conference is a meeting. It will give you the opportunity to talk to the young person about how you have been affected by what has happened and to hear why the young person has committed the offence. It gives you the opportunity to make suggestions about what the young person can do to make amends and how to stop the behaviour that caused you harm. It also gives the young person an opportunity to acknowledge their wrongdoing (Youth Justice Agency, 2013, p. 2).

For victims, restorative justice is about describing how the crime has affected their lives. This dialogue with victims enables offenders to learn of the impact of their actions and to express their own stories. It is through this process that offenders can take responsibility for what they have done, and victims can recuperate a sense of agency and control. ${ }^{3}$

\footnotetext{
${ }^{2}$ A young person who has committed a crime against an older person may be asked to volunteer at a dedicated day centre, while someone who has committed a raciallymotivated hate crime may attend a programme delivered by an organisation for ethnic minorities (Zinsstag \& Chapman, 2012, p. 5).

${ }^{3}$ Indeed, an evaluation of three schemes funded by the UK Home Office found that when it comes to the claim that restorative justice "allows victims and supporters personally to express the harm done by the offence, which might make the offender realise the extent of harm done", $83 \%$ of offenders and $60 \%$ of victims "thought the process had made the offender realise the harm caused by the offence, either very much so or to some extent" (Shapland et al., 2007, p. 38).
} 


\subsection{Narrative dialogue}

What is clear is that the task of bringing together the parties to a crime is not about 'talk for talk's sake'. It is about creating the conditions for a productive encounter founded on participation and presence, where communication between participants - both verbal and non-verbal - becomes an important medium through which justice can be experienced. As Chapman \& Chapman (2016) explain, crime is both a strategic act and a communicative action: it implies indifference to (or perhaps aggression against) another person's needs, rights, and feelings (see also Zehr \& Mika, 1998). For a person to experience a sense of justice, values that have been violated, such as respect, safety and freedom, must be restored. In the Northern Ireland model, a 'narrative dialogue' approach is taken in which the harm that has been done to these values is articulated and explored, and

victims are facilitated to tell the conference what needs had arisen from the harm and what they want done to meet these needs. To achieve this each party is enabled to give their account of the harmful incident and be heard respectfully (Chapman \& Chapman, 2016, p. 6).

This model follows the South African Truth and Reconciliation Commission by recognizing that 'truth' is multidimensional. To reach different manifestations of truth in a crime involving a young person, coordinators focus on enabling participants to tell their story in a way that suits them, starting with exploring what happened. This reaches towards the "forensic truth" of harm (Chapman \& Chapman, 2016, p.6), and refers to the objective and relevant evidence. When the coordinator asks participants to describe their story of the incident and what it means to them, this stage is directed towards the "personal truth" (p.6) of the harm. "Social truth" (p.6) comes through dialogue, as participants listen with respect to one another and, in turn, respond to what they hear. By keeping the focus on their experience of the harm, the dialogue is not about debating who is right or wrong but listening to one another's story and achieving consensus over how to proceed.

In this way, narrative dialogue "is designed to discover the specific, contingent and irreducible experience of suffering experienced by each individual" (p. 8). Here, proceedings take on an explicitly hermeneutic dimension, since the primary objective of communication between participants is to uncover meanings which, until teased out in the restorative encounter, remain hidden in the irreducible folds of individual human experience (Maitland, 2017). The excavatory impulse that drives all hermeneutic enquiry - to illuminate, decode and demystify the unknown also animates conversations in the restorative meeting, where participants are given the opportunity to listen and share in a space of safety and sensitivity, and where there is no attempt to occlude the differential, subjective and experientially-contingent nature of their stories. From a hermeneutic perspective, these narratives are many-tiered and profoundly affective interpretations of the original incident and its consequences for those involved. As interpretations, they represent the participants' acquisition of a voice, of the power to uncover hurt, and to reveal what it is they think and feel about the harm and what they need to move on.

\subsection{The hermeneutic dimension}

To read the narrative dialogue approach through the interpretation theory of Ricoeur, we might say that the restorative objective is about more than exegesis. It is about challenging the fundamental precepts of understanding that the world is constructed from the 'self' outwards and that phenomena can exist independently of our own construction. According to Ricoeur (1976), this is to do with the fundamental condition of "solitude" that characterizes 
every human being and by which the experience of one person can be neither transferred "whole as such" nor transferred to another:

My experience cannot directly become your experience. An event belonging to one stream of consciousness cannot be transferred as such into another stream of consciousness. Yet, nevertheless, something passes from me to you. Something is transferred from one sphere of life to another. This something is not the experience as experienced, but its meaning. Here is the miracle. The experience as experienced, as lived, remains private, but its sense, its meaning, becomes public. Communication in this way is the overcoming of the radical noncommunicability of the lived experience as lived (Ricoeur, 1976, pp. 15-16).

One of the lessons of Ricoeur's philosophical hermeneutics is that by exposing ourselves to the understandings of others we displace the immediacy of our own consciousness and realize that every understanding proceeds from a prior understanding of the phenomena we are engaged in interpreting. ${ }^{4}$ This circularity is not vicious but virtuous, for it stimulates thoughtful reflection and gestures towards a "second naivety" of understanding, and from there, the possibility of change, since "to understand, for a finite being, is to be transported into another life" (Ricoeur, 2005, p. 5).

This communicative mutual interdependence finds its echo in restorative justice precisely because the focus is on something greater than the turn-byturn revelation of individual experience. As Chapman \& Chapman (2016) explain, as the complexity of participants' stories becomes clear, "the parties are faced with the choice of how they will accommodate the other's story within their own account. The restorative process allows people to interact in a way that creates a social and emotional connection" (p. 9). It is only when participants interact with one another's story that the 'meaning' of the harmful event becomes mobile and the mutual exclusivity of their respective regimes of human experience transforms the dialogue into an open process that no single vision can cover. In the circular dialectic of speaking and hearing that arches outwards from one's own space of story-telling, through the space of the other and back again, narratives become enriched and the pursuit of 'objective' truth becomes less important than exploring the diversity of stories being told at any one time.

\section{Power and the interpreter}

So far, the focus of discussion in this article has been on monolingual interactions. My explanation of narrative dialogue and its relationship to an increased sense of empathy and empowerment on the part of victims and offenders, for example, presumes that participants speak the same language or share the same level of proficiency. I now wish to look beyond the monolingual to consider what may happen to the dynamics of understanding when the language of encounter (or the way language is used and understood) is not the same for all. As will be argued shortly, the use of interpreters (who are not direct parties to the harm) not only risks re-introducing the figure of the 'learned' professional to the process, but also transforming the distribution of power in ways that could militate against intended restorative outcomes.

The distribution of power in interpreter-mediated encounters has been a persistent concern in the interpreting literature over the decades, and it was

\footnotetext{
${ }^{4}$ For a cognate view in the context of interpreting in public services and the community, see Tipton and Furmanek's (2016) definition of "dialogue interpreting", which emphasizes equal, balanced, and respectful communication within a space of mutuality that calls "for an openness to the Other in order to understand oneself" ( $p$. 6).
} 
Anderson (1976) who argued that it is through the situational ambiguity that characterizes the figure of the interpreter that power is exercised. According to Anderson, because the interpreter is, by definition, bilingual, monolingual clients become dependent on the interpreter's assistance, casting the interpreter in a highly important role with regard to the clients:

$[\mathrm{H}]$ is position in the middle has the advantage of power inherent in all positions which control scarce resources. This advantage, when combined with the relative ambiguity of the interpreter's role, allows him considerable latitude in defining his own behavior vis-à-vis his clients. His behavior may, therefore, be expected to have an unusually great impact on the structure of the entire situation. The interpreter's control over the interaction pattern that develops, and thereby over the structure of the triadic relationship, is founded in his ability to translate selectively (Anderson, 1976, p. 212).

In this way, the interpreter operates as a fulcrum around which every aspect of communication turns. Power is ceded to the interpreter through clients' limited language proficiency, and it is exercised through the way in which the interpreter handles clients' words. This is a view shared by Gallai (2017), who argues that police interpreters act as "gatekeepers and/or manager of the exchange as they have more control over allocation of turns of talk" (p. 179). But, as Boéri (2015) notes, scholars and professionals tend to restrict the extent of the interpreter's involvement to that of discourse (p. 40), despite ongoing research to the contrary. Gallai's findings on the managerial role of the interpreter, for example, are set against an acknowledgement that legal interpreting "takes place within an institutional context and the setting predetermines how power is distributed among participants" (2017, p. 179). This is a view shared by Pöchhacker (2004), who writes of how "the latitude and power exercised by the interpreters in carrying out their mediating function is subject to setting-specific higher-order constraints at the interactional, socio-professional and institutional levels" (pp. 152-153). For these reasons, interpreters have been characterized increasingly in the literature as "socially responsible, less subservient agents" (Tipton, 2017, p. 238).

In the case of a restorative encounter, where "emotional dynamics" capable of engendering empathy in participants are at work (Braithwaite, 2006a, p. 395), if the interpreter does indeed enjoy an advantage of power, then it is worth considering the extent to which this advantage might affect participants' ability to empathize with one another in a conference where an interpreter is required. Given that victim-offender interactions are predicated on the centrality of participants - their story, their experience of harm, and their decision as to how it should be addressed - any influence the interpreter exerts over the pattern of interaction, and any resultant impact on participants' ability to achieve a voice and sense of empowerment, beg further scrutiny.

\subsection{Interpreter codes of conduct}

Much attention in the interpreting literature has been paid to the extensive ethical codex that regulates the professional conduct of interpreters in the UK. Unlike professionals such as solicitors, who must complete formal education in ethics and subscribe to contractually enforced codes of conduct, interpreter codes of professional practice tend to be advisory or educational, apply only to those who join particular professional associations, regularly contradict one another, and offer no guidance when users are subject to more than one code simultaneously (Drugan, 2017, p. 127). Such codes of practice stipulate, for example, that interpreters should undertake only those commissions which they believe to be within their linguistic and subject-area competence, and that 
confidentiality and impartiality should be maintained at all times (Institute of Translation and Interpreting (ITI), 2016; Chartered Institute of Linguists (CIOL), 2017; and National Register of Public Service Interpreters (NRPSI), 2016). Interpreters should "faithfully translate, interpret or otherwise transfer meaning" (NRPSI, 2016, para. 5.4), or "take all reasonable steps to ensure complete and effective communication between the parties" (ITI, 2016, para. 4.1 , and when tackling discriminatory comments in a court case, interpreters are obliged professionally "to provide accurate translation or interpretation of specific content" (CIOL, 2017, para. 8.4). Scholars have highlighted how these principles of accuracy and neutrality are underpinned by narrow conceptualizations of the interpreter's role and are often refused by the concrete realities of public service interpreting (see surveys by Stern, 2011, and Maltby, 2010). According to a positivist view of language, and, by extension, assumptions in the codex surrounding the work of the interpreting professional, language functions as a transparent code, such that 'meaning' is viewed as a stable essence that passes unproblematically from one person to another through speech. This legitimizes a conceptualization of interpreting as a simple matter of shifting between codes: one word is replaced with another and the meaning remains intact. It is this view of language that in turn leads to the idea that it is possible to translate between languages without engendering change and thus adhere to a code of conduct predicated on interpreting "truly and faithfully what is uttered, without adding, omitting or changing anything" (NRPSI, 2016, para. 5.4). "Since the interpreter is viewed as a mere presence with no active engagement with what he or she is interpreting", Maltby (2010) writes, "interpreter impartiality and neutrality are taken for granted and are assumed to remain unchanged throughout the duration of the interpreted interaction" (p. 208). Yet numerous studies support the assertion that interpreters are not disinterested machines, transporting reified units of sense between monolingual parties, but active participants with a clear influence over the shape of discussions (see Mason, 1999, and Tipton \& Furmanek, 2016).

\subsection{The agency of the interpreter}

As already suggested, of particular scholarly concern is the exercise of power in interpreter-mediated criminal justice settings (see Hale, 2008, Martín \& Phelan, 2010, and Gallai, 2017), where despite the prevailing notion of the interpreter as an objective figure, the purposeful and highly strategic use of language that is common in the oppositional justice system means that interpreters must simultaneously translate the words that people say and make interpretive judgements as to the rhetorical purpose behind them. "The interpreter's very difficult role", Hale (2008) writes, "is to attempt to understand the intention of the utterance and portray it as faithfully as possible in the other language" (p. 115). In this way, the attainment of 'faithfulness' and 'accuracy' involves working on the level of meaning rather than at the level of word (Martín \& Phelan, 2010, p. 8). According to Wadensjö (2014), "[i]nterpreters on duty understand themselves not only to be translating between two languages, but also to be performing on others' behalf various activities, such as persuading, agreeing, lying, questioning, claiming, explaining, comforting, accusing, denying, coordinating interaction, and so forth" (p. 42). Interpreters thus become involved in the evolution of discussions, to understand the motivation behind a given statement in one language and to translate it in such a way that the objective they have imputed can be fulfilled as much as possible in the other.

When confronted with unfamiliar phrases or dialectally or regionallymarked lexis in testimony, immigration interpreters, for example, resort to a range of emphatic strategies through which to seek clarification and which, in turn, have a dramatic effect on the testimony recorded. These strategies reflect 
how interpreters intervene actively in the construction of meaning, and, by extension, the representation of linguistic and cultural otherness in the interpreter-mediated criminal justice setting, since it is interpreters who decide what to say and what to omit, when to interrupt or when to change the questioning style to acquire more relevant information (Vargas-Urpi, 2016, p. 675). Gallai's (2017) study of police investigative interviews, for example, found that utterances by primary participants are subject to distortion, omission or amplification when translated by interpreters. These are so subtle that neither the police officer nor the interviewee notices the resulting miscommunication and no compensatory moves are made. This leads to a reification of the miscommunication "on tape, in the transcript and, therefore, at trial" (p. 190). Where oral and written records of proceedings or audio recordings of telephone encounters and video recordings of interviews are available, therefore, interpreters' choices can be questioned, both in courts and in lawsuits.

What is clear is that in addition to facilitating communication, interpreters also fulfil a mediatory role:

In testimony mediated by an interpreter, the choice of words remains in the hands of the interpreter. It is the interpreter's word choice that remains on the record, and that is heard and repeated in subsequent questions posed by other attorneys and the immigration judge. Whether or not interpreters are consciously aware of their linguistic coerciveness, they engage in an active reconstruction of events according to their own particular perspective and circumscribed by their knowledge of sociolinguistics or lack thereof (Zambrano-Paff, 2011, p. 199).

As "professionalized intermediaries" in the process of negotiating meaning, while the primary task of interpreters may be one of service provision, interpreters must therefore also exercise a degree of control (Wadensjö, 2014, p. 68), suggesting an aporia between the obligations enshrined in codes of conduct for interpreters working in public service contexts and the "observable dynamics which unfold in mediated interactions" (Maltby, 2010, p. 210).

\subsection{The role of empathy}

For those concerned with the dynamics of conversation between participants in the bi- or multilingual restorative conference setting, where every aspect of the communicative situation is designed to offer an alternative to the oppositional discourse associated with courtroom contexts, the question that must be answered is whether this aporia actually limits the effectiveness of the storytelling process and puts victim and offender satisfaction at risk. As Harris et al. (2004) urge,

[a] central part of every conference is each person's account of how the offence has affected him- or herself and other people. Usually, the most important story is that of the direct victim. Confronted with the victim's suffering and the suffering of their own loved ones, offenders often, but not always, will be touched by compassion (Harris et al., 2004, p. 200).

If the conference goes well, the offender comes to understand the suffering of the victim and that it has been caused by the offender's behaviour. Feelings of "remorse and shame-guilt" can emerge or become concretized (p. 201), and if the offender takes the step of offering an apology, they make themselves vulnerable by submitting to the possibility that the victim may not accept it. This enables the offender to start to recognize the victim as a bearer of rights, and relies on the production of empathy, identification and a new- 
found ability to imagine the position of the other. Here, participants' communities of support play a crucial part:

[T] he role that others play in reinforcing the conclusion that the offender's behaviour was wrong can also be important. In some cases offenders will be impervious to victims' stories and it is only through the effect of the story on the offender's supporters, who do empathize with the victim, that the offender is affected. Even implicit acceptance by the offender's supporters of the victim's story can be important because their opinion is harder for the offender to ignore (Harris et al, 2004, p. 201).

Taking active 'responsibility' for an injustice depends on giving an account of that responsibility (Braithwaite, 2006b, p.48) in a deliberative situation in which the stakeholders to an injustice are given the opportunity to participate in articulating and defining what 'responsibility' should look like (p. 43). In a setting where the hope of enabling victims to feel "restored in dignity and in citizenship" (p. 203) is linked directly to the promotion of "social processes that involve the disapproval of offending" (p. 192), the production and experience of affect goes hand-in-hand with participants' twin roles as listeners and storytellers:

Empathy for victims' suffering causes the offender to recognize the hurt their behaviour caused and in turn is an important pathway to recognizing that it was wrong. Thus, it is often empathy that leads to the emotions of remorse, guilt and shame. As a consequence, it is critical to activate the potential for compassion in the offender. This can happen only in a situation wherein the offender him- or herself experiences respect and empathy (Harris et al, 2004, p. 202).

What effect the presence of an interpreter will have - if any - on the 'activation' of empathy (as well as remorse, guilt, shame, vindication, dignity or recognition), the taking of responsibility, or the facilitators' ability to build rapport and create an atmosphere of safety and relaxation, will depend on the interpreter's concrete involvement in the dynamics of restoration in the conference room, on their skills, training, and attitudes, and on the specific ways in which they interact with participants. It is to this space that I now turn my attention.

\section{Preparing for a conference}

Before we imagine what a restorative conference might look like when communication between participants is supported by an interpreter, we must first ascertain what it is that the interpreter is called to communicate. In some models of restorative justice, including certain processes in operation in the USA and Australia, facilitators take a script-based approach, adhering to a carefully crafted structure and set of questions aimed at progressing certain strategic restorative outcomes. In Northern Ireland no formal script is followed, and coordinators design each encounter to match the unique needs and wants that arise when preparing participants to take part. This means that the contours of youth conferences in Northern Ireland are necessarily flexible and non-prescriptive, and no two conferences will look exactly the same. They are structured enough to ensure that all parties feel in control of what they want to say and ask, but also sensitive to the needs of different participants.

Given that the socio-institutional framework surrounding the conference is characterized by asymmetries of power, the primary task of the coordinator is to tackle unequal power relationships - between the victim and offender and between the individual participants and the organs of the oppositional criminal 
justice system as traditionally conceived. But while the RJC signals "communication skills of participants" and "English language skills - consider the need for an interpreter" (Restorative Justice Council, 2016, p. 17) as factors that may be relevant to a facilitator's assessment of risk prior to embarking on a restorative process, neither the RJC guidance nor the national occupational standards explain how an interpreter may influence the process of building participants' trust and confidence in either the process or the competence of the facilitator leading it. While the national occupational standards point towards the risks associated with bi- or multilingual restorative encounters, much work remains to be done to identify exactly how these risks are manifested and how to prevent them. Despite a view of the interpreter as a 'non-person', that is, someone who would play a technical role but who would not be counted as fully 'present' in the communicative situation (Wadensjö, 2014, p. 67), the interpreter plays an instrumental role in enabling all participants to communicate across these asymmetries of power, knowledge and experience. As we saw in Anderson (1976), it is this very dependency on the interpreter's service that in turn affords interpreters their own position of power:

When interpreters give voice to others and listen on others' behalf they provide a certain service, and simultaneously they also fill a function in the institutional system of control, by seeing to it that interaction continues, that a certain agenda is kept; that the professional party may inform and the layperson gets informed. Interpreters can be perceived as actors within the service system of the society, and at the same time within the public system of control (Wadensjö, 2014, p. 13).

The RJC guidance and the national occupational standards make an explicit link between the communication needs of conference participants and the exercise of power associated with the use of interpreters. What has not yet been produced, however, is detailed qualitative research into these questions, and any effect the interpreting process has on the ideals of fairness, dignity and respect enshrined at the meta-level of restorative practitioner regulations is currently unknown. Such detail could be yielded, for example, through observational and interview-based data gathering processes, recording the full spectrum of interlingual interactions between facilitators and participants, between participants themselves, and between participants and their supporters. Attention should be paid not only to final stage face-to-face encounters but also to preparatory discussions between parties. Given that participants' language needs are not necessarily restricted to the spoken domain, researchers might also focus on written communication during the preparatory stage between the organisations charged with leading restorative processes and the full range of participants within them.

\subsection{Inside the conference}

Following the preparation stage, and if the parties agree to take part, a youth conference in the Northern Ireland setting will be organized in an appropriate venue that meets the needs of all participants. The coordinator opens the conference by reminding everyone why they are present, restates the ground rules and invites each person to introduce themselves. The police officer is asked to state what happened factually and in ordinary language (rather than in the discourse of court evidence). The person responsible for the harm is asked to account for what he or she did to cause the harm. The victim is invited to ask the offender any questions and to state how the incident affected them. Other members are also asked to comment. The coordinator will then invite the young person to respond to what they have heard, and a dialogue is facilitated on what needs to be done to meet the victim's needs arising from the harm. When certain that the victim is as satisfied as they are going to be, 
the coordinator asks the young person and their supporters what needs to be done to meet their needs associated with the harmful act. The victim and any professionals present are also asked to suggest what needs to be done to meet the young person's needs. Once an agreement has been reached, it is written up and signed by all.

Inside the conference, the triangular pattern of discourse between the victim, offender and coordinator reflects the triadic relationship that connects a victim, an offender and the community at societal level. Cohen (2012) has written that even when family members or community supporters are present for the victim or the offender, all participants are cast under one of the three primary roles, such that the triad is one of: "victim (and supporters), offender (and supporters), or facilitator" (p. 391). This configuration can be visualized thus:

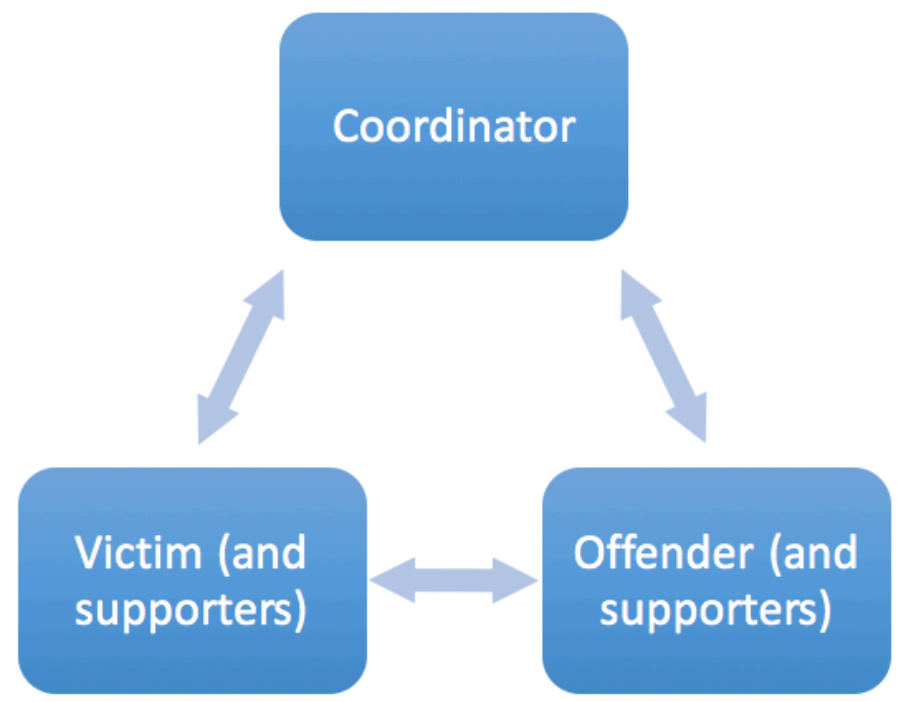

Figure 1. Triadic pattern of communication in the monolingual restorative justice conference.

However, given that a youth conference in the Northern Ireland context is participant-centred and participant-led, where everything about the shape and nature of the meeting is designed to enable members to enter into a safe, open and honest dialogue with one another, Cohen's description ignores the communicative realities of multi-directional discourse in the conference room, since every participant (not just the victim and offender) enjoys the freedom and flexibility to enter into discussion with any other person present. Even in a monolingual restorative encounter, therefore, when supporters for the victim and offender take part, the social relation is not triadic but quintetic: victim, offender, coordinator, supporter(s) for the victim, and supporter(s) for the offender. Each participant has up to four choices of interlocutor, and because every interlocutor is free to reply to every statement that is made, the direction of conversational travel can take up to ten different courses: 


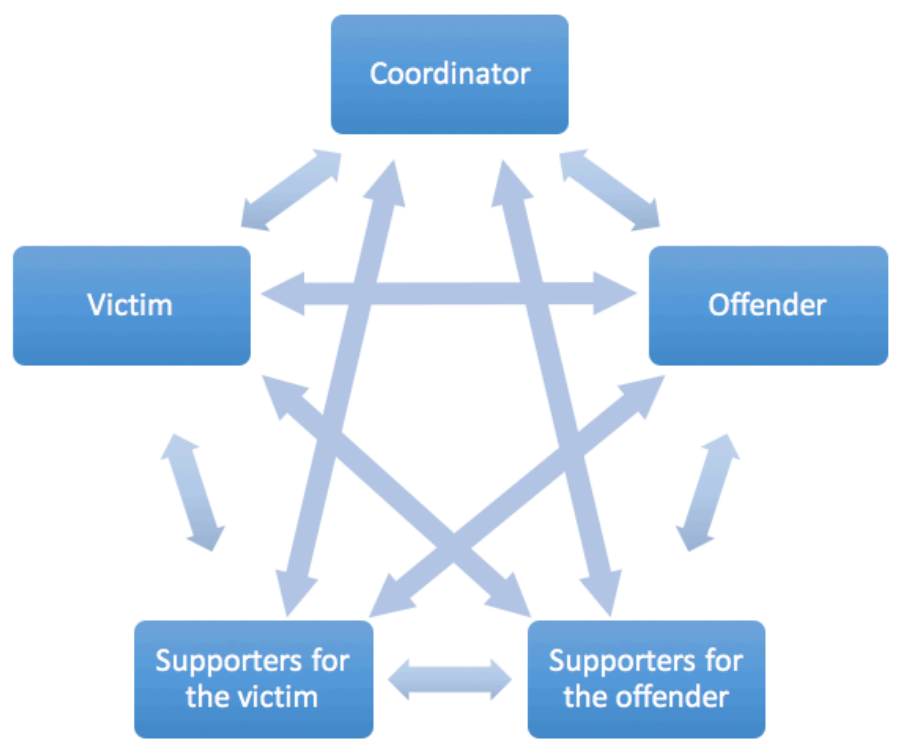

Figure 2. Quintetic pattern of communication in the monolingual restorative justice conference.

Each potential line of communication is two-way: the victim can ask the offender a question and the offender can respond directly to the victim, and so on. In parallel with the ten potential lines of restorative enquiry - and potentially doubling the number of communicative channels to twenty - are the 'backchannel' meta-responses that run secondary to the predominant channel of communication and by which conference participants receive a degree of on-the-fly feedback from their listeners. When a social worker, lawyer, community representative, police officer or co-facilitator is included, the number of potential interlocutors - and with it the number of potential lines of enquiry - increases further. Even in monolingual settings, then, the nature of restorative conversation is rich, complex, and must be carefully managed. It is for this reason that practitioners are advised to focus on facilitating dialogue in ways which "keep the focus on participants' communication with one another", "encourage everyone to contribute actively and fully", and "move the process forward at a pace that balances the needs of everyone involved, taking into account the time and resources available" (Restorative Justice Council, 2016, p. 21).

\subsection{Conceptualizing the challenges of an interpreter-mediated conference}

In contrast to monolingual interactions, in a conference where an interpreter is commissioned to render consecutively in another language the words of every speaker when they reach the end of a complete thought or 'paragraph' of speech, all communication, including interventions by the coordinator aimed at maintaining the focus and moving the process forward, must be re-routed through the interpreter. While the social relation between participants now increases from the quintetic to the sextetic, in effect, all direct communication between participants who do not share the same language is suspended, such that every statement directed at a particular participant must also be directed at the interpreter, who will then relay it to the intended recipient in the other language of the conference: 


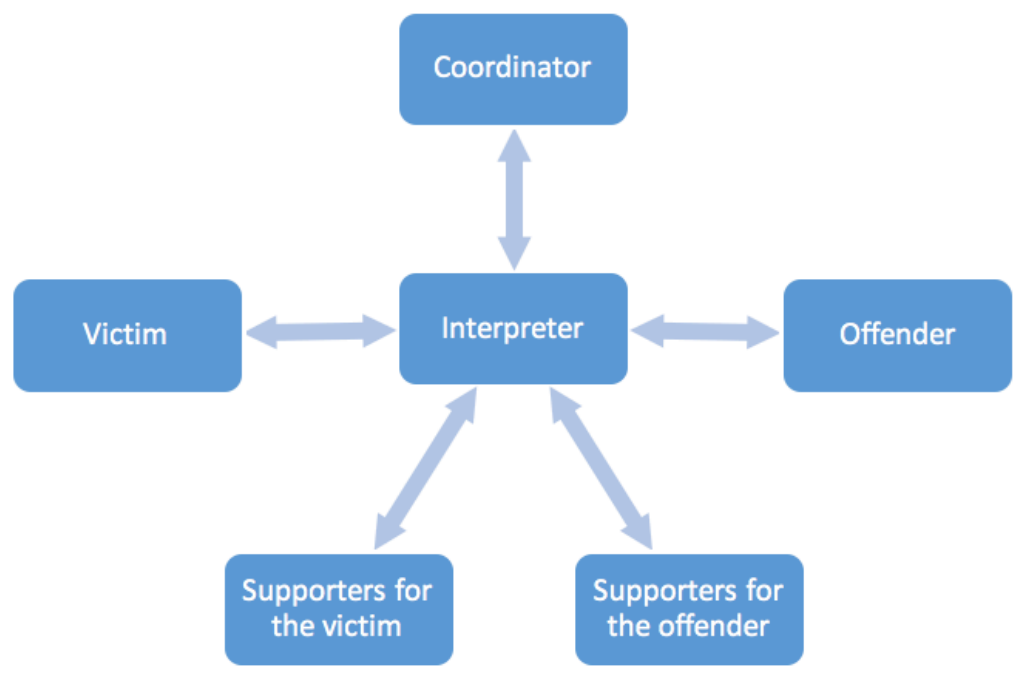

Figure 3. Interpreter-mediated communication in the bilingual restorative justice conference.

It is important to note that while this figure suggests the physical presence of an interpreter at the centre of a circle of participants, in a realworld setting it would not be likely for an interpreter to be positioned in this way. This is a point to which I will return in more detail shortly; what I wish to emphasize here from a strictly linguistic (rather than spatial) perspective, is that it is the interpreter who speaks for and on behalf of all participants in the room. This means that the sense of agency victims and offenders can experience as a result of the multidirectional channels of communication at their disposal in monolingual restorative conferences must give way to a situation in consecutively-interpreted conferences in which every speech act, though spoken by someone with the theoretical agency to speak, must in practice be spoken again by the interpreter. Despite the potential for up to ten separate lines of communication, and although it is unlikely for an interpreter to be located physically at the centre of the seating arrangement, participants must nonetheless direct all speech through the interpreter in the first instance. Conversation remains interactive, in the sense that every participant continues to enjoy the same opportunity to communicate with everyone else, but it is a form of interaction that takes place in a space of suspended animation.

The coordinator will open proceedings in the usual way by asking the young person to tell the victim what they did and how they feel about it now. But in a conference where the consecutive mode of interpreting is privileged (rather than a simultaneous mode facilitated by portable headsets and microphones), when the offender starts to speak in their own language, the victim, speaking a different language, may hear the way in which the offender speaks, and see their facial expressions, gestures, eye movements, and use of space, but may not understand what the offender has said until the interpreter has translated their words into the language of the victim. If the victim then wishes to share with the offender about the impact the crime has had upon them, while they may use eye contact or body language to indicate that their story is intended for the offender, the victim must, in a practical sense, ensure that their speech is either directed towards, or at least 'heard' by, the interpreter. The victim must wait while the interpreter relays the victim's remarks in the language of the offender and must further wait while the offender responds to the interpreter, and the interpreter relays their response. It is not until both the victim's remarks and the offender's response have each been relayed in the different languages of the conference that the circle of 
communication that was opened with the victim's first statement can be closed. In reality, of course, participants may have different levels of language proficiency and the degree to which they depend on the interpreter may differ. But in a technical sense, when it comes to 'dialogue' (understood as an exchange of discourse between two or more actors as interlocutors in the back-and-forth development of a conversation), no participant in an interpreter-mediated restorative conference where the turn-taking mode of speech holds primacy can enter into true dialogue with an interlocutor since it is first and foremost the interpreter who does the job of interlocution on their behalf.

\section{Discussion}

Braithwaite (2006b) writes of how restorative justice views it as "morally important to give an opportunity for all those who see themselves as key stakeholders in an alleged injustice to participate in the deliberation about what to do" (p. 35-36). It is for this reason that the principal form of deliberation is among people seated in a circle, in contrast to two people negotiating across a table (p. 36). It is the immediacy of face-to-face encounters between the primary parties to a crime, and the directness of connection between what they 'hear' from each other and what they 'see' the body language of sincerity, shame, anger, humiliation, sadness, fear, etc. that has the power to move those involved. Careful consideration in advance of a conference as to the seating arrangement (where to locate the interpreter with respect to the circle), the role of eye contact, body language and voice; as well as the use of portable simultaneous interpreting equipment could all help to mitigate the 'fulcrum effect' associated with the interpreter's role. Highly skilled interpreters, with the right training, and attitudes attuned and appropriate to the unique communicative needs and intended outcomes of restorative conferences, could make a real difference to participants' experience of the encounter.

The foregoing suggests an urgent need to lift the lid on interpretermediated conferences: to examine exactly who it is that provides interpreting at such conferences (encompassing analyses of their skill level and training, their attitudes and understanding of the process, professional status, etc.); what it is they say and how they say it; and to evaluate the views of victims and offenders. In an encounter where victim empowerment and the development of productive emotions of remorse and shame on the part of the offender depend on the immediacy and intimacy of dialogue, the turn-taking system of consecutive interpreting presents considerable challenges. The asynchronous quality of this form of interpreter-mediated communication could risk imposing the highly structured on the necessarily flexible - such as the Northern Ireland model, which is predicated on the avoidance of prescriptivism in favour of participant-centred discussions, where it is the coordinator's job to ensure everyone's equal participation while at the same time avoiding the limelight. In the absence of a technological setup that facilitates simultaneous interpreting through microphones and receivers, where the experience of the other person's words is not direct but through the re-worded representation of their words by the interpreter, it is worth exploring whether this has an impact on participants' ability to develop empathy, or to experience remorse or shame.

"Being in settings where they appear to be experts on language and culture", Wadensjö (2014) writes, "interpreters run the risk of depriving the primary parties, especially the laypersons, of power and responsibility" (p. 281). This is because, she explains, to engage in spoken interaction means coordinating what one wishes to say with everything that is being said by 
everyone else. It means playing an active role, as both a speaker and a listener, in the conversational ebb and flow, responding flexibly to the organic nature of discourse as a live event (pp. 152-153). In conversations mediated by an interpreter, therefore, the choices interpreters make as dynamic participants in the conversational encounter play a significant role in transforming how discourse develops:

What interpreters on duty say is responsive to the primary interlocutors' immediately prior talk. In an interpreter-mediated conversation, the progression and the substance of talk, the distribution of responsibility for this among cointerlocutors, and what, as a result of interaction, becomes mutual and shared understanding - all will to some extent depend on the interpreter's words and deeds (Wadensjö, 2014, p. 195).

These choices, in turn, will depend on the interpreter's level of skill, their degree of training, their willingness to cede control in discussions, and their potential for bias, among others. The challenge for restorative practitioners is not just that interpreting transforms participants' speech, or that an interpreter's individual competencies, experiences, biases, and knowledge inform how they act and interact. Practitioners must also face the possibility that the very presence of an interpreter may "influence the co-construction of meaning" (Gallai, 2017, p. 190) and thus transform how victims and offenders speak in the first instance. In a consecutively-interpreted bi- or multilingual conference, since the role of coordinating talk and managing turn-taking must be shared between facilitator and interpreter, a degree of power must be ceded, an insight which resonates with scholars' insistence that interpreters are not only providers of a service but also agents of authority and control (see Wadensjö, 2014, and Tipton, 2010). If, as Christie (1977) contended, conflicts are "taken away, given away, melt away, or are made invisible" (p.7) by legal actors and the organs of the state who "steal" them (p. 4; p. 7) from victims by limiting their agency and restricting their involvement in the criminal justice process, then in conferences where the turn-taking model of consecutive interpreting is privileged there is a risk that the communicative centrality of the interpreter could reinstall the learned professional at the heart of criminal proceedings. By displacing those most directly affected by crime to the linguistic margins, in other words, restorative practitioners could 'steal back' from participants the very conflict that had been returned to them through the provision of the restorative conference.

The role of the wider community within the restorative encounter must also be viewed through the prism of interpreting. Zehr and Mika (1998) contend that the justice process belongs to the community; that it draws from community processes, contributes to community building, and plays a part in trying to prevent similar harms (p. 53). Yet, as Hoyle \& Fonseca Rosenblatt (2016) show, there are cases of restorative justice with little community involvement or no "genuine inclusion of the community", where the participation of victims' and offenders' direct supporters (such as parents or other relatives) is conflated with that of representatives of a wider community harmed by the offence (p. 40). Given that an interpreter's influence on the evolution of dialogue transforms their role from the pursuit of detached impartiality into one of active participation, future research might address the extent to which interpreters are already being drawn (or could be drawn) from the very communities for whom they are interpreting.

There is also potential for future research into what use (if any) the restorative justice sector currently makes of volunteer interpreters. In her 2017 study of the role played by professional and non-professional volunteer interpreters in the care trajectories and institutional itineraries of survivors of domestic abuse, Tipton found that although professional interpreters mediated initial contact between service users and the charity she studied, non- 
professional volunteers with language skills were used to support informal interactions such as drop-in sessions and group activities, producing a significant attendant impact on a service user's institutional itinerary. "Since the majority of volunteers are former service users", she writes:

there is a level of solidarity with current service users that can support resilience building ways that professional, impartial interpreter-mediated encounters cannot. This means that while there is no suggestion that the organisation considers volunteer services as a replacement for professional language service provision, there is some evidence to suggest it can support the creation of cultures of safety and service user empowerment (pp. 249-250).

While Tipton makes clear that she does not view volunteer approaches "as a durable component of organisational life or as a stop-gap for underfunded professional interpreting", the non-professional volunteer provision emerges in her study as "salient and worthy of consideration" (p. 251) and suggests a need to identify and map any provision of a similar nature in the restorative justice sector.

\section{Conclusions}

While it is possible to raise questions on a theoretical level, the substantive research that would shed light on the concrete praxis of restoration in the interpreter-mediated encounter has not yet been undertaken. What is needed at this time is data. In addition to the concrete examples from interpreted restorative justice conferences that would allow researchers to place their theoretical contentions on language and restorative justice into a practical context, it is important to find out the number of people needing an interpreter who are offered restorative conferences as an alternative to courtroom-based justice; what happens inside those conferences when they do take place; and to what extent victims and offenders feel satisfied with the process. It is also important to investigate how empathy is produced when victims and offenders share their stories through an interpreter, and to measure what impact interpreter-mediated restorative encounters have on recidivism rates and participants' ability to move on.

Such research should explore the types of interpreter commissioned to work in restorative conferences: where they are from; what communities they feel they represent; how they are commissioned; whether they are professional or non-professional; what experience and training they have in a specifically restorative justice context; and to what extent they are involved at the preparation stage. Researchers could engage with questions of implicit bias within the context of restorative justice interpreting; interpreters' level of skill and degree of training (encompassing both interpreting within alternative criminal justice settings and trauma-informed interpreting); and their attitudes to the process, by exploring the extent to which they feel they must intervene occasionally, become involved actively, or take control. Researchers could also explore connections with cognate areas of professional practice and interpreter training such as trauma-informed interpreting, and the ways in which restorative justice training could serve interpreters across everyday community and public service interpreting encounters. By suggesting at the level of theory some of the potential consequences for participant empowerment resulting from the linguistic centrality of the interpreter within the restorative conference paradigm, I have sketched pathways for future empirical research and argue for a holistic approach that would combine a sensitivity to questions of translation, language, and communication in the restorative encounter with the continued analysis of the means and methods of restorative justice practice. 


\section{Acknowledgement}

The author is grateful to the reviewers for their level of engagement with this work and for their thoughtful and constructive feedback.

\section{References}

Anderson, R. B. W. (1976). Perspectives on the role of interpreter. In R. W. Brislin (Ed.), Translation: Applications and research (pp. 208-228). New York, NY: Gardner Press.

Boéri, J. (2015). Key internal players in the development of the interpreting profession. In H. Mikkelson \& R. Jourdenais (Eds.) The Routledge handbook of interpreting (pp. 29-44). London, England: Routledge.

Braithwaite, J. (2006a). Doing justice intelligently in civil Society. Journal of Social Issues, 62(2), 393-409. doi:10.1111/j.1540-4560.2006.00456.x

Braithwaite, J. (2006b). Accountability and responsibility through restorative justice. In M. Dowdle (Ed.) Public accountability: Designs, dilemmas and experiences (pp. 33-51). Cambridge, England: Cambridge University Press.

Chapman, T. (2012). Facilitating restorative conferences. In E. Zinsstag \& I. Vanfraechem (Eds.), Conferencing and restorative justice: International practices and perspectives (pp. 65-82). Oxford: Oxford University Press.

Chapman, T., \& Chapman, A. (2016). Forgiveness in restorative justice: Experienced but not heard? Oxford Journal of Law and Religion, 5(1), 135-152. doi:10.1093/ojlr/rwv066

Chartered Institute of Linguists (2017). Code of professional conduct. Retrieved September 23, 2018 from http://www.ciol.org.uk/sites/default/files/Code.pdf

Christie, N. (1977). Conflicts as property. British Journal of Criminology, 17(1), 1-15. doi:10.1093/oxfordjournals.bjc.a046783

Cohen, R. (2012). Resource theory and restoration: What is restored in restorative justice? In K. Törnblom \& A. Kazemi (Eds.), Handbook of social resource theory: Theoretical extensions, empirical insights, and social applications (pp. 383-396). New York, NY: Springer.

Drugan, J. (2017). Ethics and social responsibility in practice: Interpreters and translators engaging with and beyond the professions. The Translator, 23(2), 126-142. doi:10.1080/13556509.2017.1281204

Gallai, F. (2017). Pragmatic competence and interpreter-mediated police investigative interviews. The Translator, 23(2), 177-196. doi:10.1080/13556509.2017.132731 7

Gerkin, P. (2012). Who owns this conflict? The challenge of community involvement in restorative justice. Contemporary Justice Review, 15(3), 277-296. doi:10.1080/10282580.2012.707423

Hale, S. (2008). Controversies over the role of the court interpreter. In C. Valero Garcés \& A. Martin (Eds.), Crossing borders in community interpreting: Definitions and dilemmas (pp. 99-121). Amsterdam, The Netherlands: John Benjamins.

Harris, N., Walgrave, L., \& Braithwaite, J. (2004). Emotional dynamics in restorative conferences. Theoretical Criminology, 8(2), 191-210. doi:10.1177/13624806040 42243

Hoyle, C., \& Fonseca Rosenblatt, F. (2016). Looking back to the future: Threats to the success of restorative justice in the United Kingdom. Victims \& Offenders, 11(1), 30-49. doi:10.1080/15564886.2015.1095830

Institute of Translation and Interpreting (2016). Code of professional conduct. Retrieved September 23,2018 from https://www.iti.org.uk/attachments/article/15 4/Code $\% 20$ of $\% 20$ Professional $\% 20$ Conduct $\% 2029 \% 2010 \% 202016$.pdf

Maitland, S. (2017). What is cultural translation? London, England: Bloomsbury Academic.

Maltby, M. (2010). Institutional identities of interpreters in the asylum application context: A critical discourse analysis of interpreting policies in the voluntary sector. In M. Baker, M. Olohan \& M. Calzada Pérez (Eds.), Text and context: Essays on translation and interpreting in honour of Ian Mason (pp. 209-233). London, England: Routledge. 
Martín, M., \& Phelan, M. (2010). Interpreters and cultural mediators - different but complementary roles. Translocations: Migration and Social Change, 6(1).

Mason, I. (1999). Dialogue interpreting. Manchester, England: St. Jerome.

National Register of Public Service Interpreters. (2016). Code of professional conduct. Retrieved September 23, 2018 from http://www.nrpsi.org.uk/for-clients-ofinterpreters/code-of-professional-conduct.html

Pöchhacker, F. (2004). Introducing interpreting studies. London, England: Routledge.

Restorative Justice Council. (2016). RJC practitioners handbook. Retrieved September 23, 2018 from https:/www.restorativejustice.org.uk/sites/default/files /resources/files/Practitioners\%20Handbook_0.pdf

Restorative Justice Council. (n.d.) Criminal justice. Retrieved September 23, 2018 from https://www.restorativejustice.org.uk/criminal-justice

Ricoeur, P. (1976). Interpretation theory: Discourse and the surplus of meaning. Fort Worth, TX: Texas Christian University Press.

Ricoeur, P. (2005). The Conflict of interpretations: Essays in hermeneutics (K. McLaughlin, R. Sweeney, W. Domingo, P. McCormick, D. Savage \& C. Freilich, Trans.). London, England: Continuum.

Shapland, J., Atkinson, A., Atkinson, H., Chapman, B., Dignan, J., Howes, M,. ... Sorsby, A. (2007). Restorative justice: The views of victims and offenders. The third report from the evaluation of three schemes. London, England: Ministry of Justice.

Skills for Justice (2013a). SFJDJ102: Engage with and prepare participants for a restorative process. Retrieved January 28, 2019 from https://www.ukstandards. org.uk/PublishedNos-old/SFJDJ102.pdf

Skills for Justice (2013b). SFJDJ201: Facilitate participants' interaction within a restorative process. Retrieved January 28, 2019 from https://www.ukstandards. org.uk/PublishedNos-old/SFJDJ201.pdf

Skills for Justice (2013c). SFJDJ202: Co-work within the restorative process. Retrieved January 28, 2019 from https://www.ukstandards.org.uk/PublishedNosold/SFJDJ202.pdf

Skills for Justice (2013d). SFJDJ204: Facilitate informal restorative processes. Retrieved January 28, 2019 from https://www.ukstandards.org.uk/PublishedNosold/SFJDJ204.pdf

Skills for Justice (2013e). SFJDJ206: Use interpreters in restorative processes. Retrieved January 28, 2019 from https://www.ukstandards.org.uk/PublishedNosold/SFJDJ206.pdf

Stern, L. (2011). Courtroom interpreting. In K. Malmkjær \& K. Windle (Eds.), The Oxford handbook of Translation Studies (pp. 325-342). Oxford, England: Oxford University Press.

Suzuki, M., \& Wood, W. (2017). Co-option, coercion and compromise: Challenges of restorative justice in Victoria, Australia. Contemporary Justice Review, 20(2), 274-292. doi:10.1080/10282580.2017.1311194

Tipton, R. (2010). On trust: Relationships of trust in interpreter-mediated social work encounters. In M. Baker, M. Olohan \& M. Calzada Pérez (Eds.), Text and context: Essays on translation and interpreting in honour of Ian Mason (pp. 188208). London, England: Routledge.

Tipton, R. (2017). Contracts and capabilities: Public service interpreting and third sector domestic violence services. The Translator, 23(2), 237-254. doi:10.1080/13556509.2017.1280875

Tipton, R., \& Furmanek, O. (2016). Dialogue interpreting: A guide to interpreting in public services and the community. London, England: Routledge.

Vargas-Urpi. M. (2016). Problems and strategies in public service interpreting as perceived by a sample of Chinese-Catalan/Spanish interpreters. Perspectives, 24(4), 666-678. doi:10.1080/0907676X.2015.1069861

Wadensjö, C. (2014). Interpreting as interaction. London, England: Routledge.

Youth Justice Agency. (2013). Youth conference: Information for victims. Retrieved September 23, 2018 from https://www.justice-ni.gov.uk/sites/default/ files/ publications/doj/yja-leaflet-youth-conference-information-for-victims-nov-2013$0 . p d f$

Zambrano-Paff, M. (2011). The impact of interpreters' linguistic choices in bilingual hearings. In L. A. Ortiz-López (Ed.), Selected proceedings of the 13th Hispanic Linguistics Symposium (pp. 190-202). Somerville, MA: Cascadilla Proceedings Project. 
Zehr, H., \& Mika, H. (1998). Fundamental concepts of restorative justice. Contemporary Justice Review, 1, 47-55.

Zinsstag, E., \& Chapman, T. (2012). Conferencing in Northern Ireland: Implementing restorative justice at the core of the criminal justice system. In E. Zinsstag \& I. Vanfraechem (Eds.), Conferencing and restorative justice: International practices and perspectives (pp. 173-203). Oxford: Oxford University Press. 